\title{
МЕСТО МИТОХОНДРИЙ \\ В СИСТЕМАХ ПОИСКА НЕЙРОАКТИВНЫХ ЛЕКАРСТВЕННЫХ ПРЕПАРАТОВ
}

\author{
Е.Ф. Шевцова, Е.А. Пушкарева, С.О. Бачурин \\ Федеральное государственное бюджетное учреждение науки Институт физиологически \\ активных веществ Российской академии наук (ИФАВ РАН), \\ 142432, Московская область, г. Черноголовка, Северный проезд, 1.
}

DOI: 10.19163/MedChemRussia2021-2021-82

E-mail: e.f.shevtsova@gmail.com

Нарушения митохондриальных функций в последние годы показано для значительного количества патологий, включая сердечно-сосудистые заболевания, иммунодефицитные и аутоиммунные состояния и значительное число неврологических патологий. Выделена отдельная группа митохондриальных заболеваний, состав которых увеличивается в результате включения новых патологий [1]. С другой стороны, для значительного числа лекарственных препаратов механизм побочных токсических эффектов связан с нарушениями функций митохондрий [2]. Это обусловило значительный интерес к митохондриям как мишеням при поиске новых лекарственных препаратов [3] и мишеням для in vitro предсказательной оценки потенциальной токсичности, в большинстве кардио- и/или гепатотоксичности, новых препаратов. Количественная оценка тканеспецифической, вызванной лекарством митохондриальной токсичности на ранней стадии разработки препарата является очевидной необходимостью для разработки лекарств и фармакологии безопасности.

Таким образом, важной задачей является формирование системы методов, способных обеспечить как оценку токсичности, так и оценку нужного терапевтического эффекта соединений на уровне митохондрий. В докладе будут представлены данные о такой системе для поиска потенциальных лекарственных препаратов для лечения нейродегенеративных заболеваний и ряда других неврологических патологий, приведены примеры её применения.

\section{Литература}

[1] https://www.umdf.org/what-is-mitochondrial-disease-2.

[2] Nadanaciva S, Will Y. Current Protocols in Toxicology/Editorial Board, Mahin D Maines (editor-in-Chief) [et Al] 2009 Chapter 2: Unit 2.15-Unit 12.15.

[3] Shevtsova, E.F., et al., Med Res Rev, 2021. 41(2): p. 803-827. 